DOI: $10.18413 / 2658-6533-2019-5-4-0-11$

\title{
О.В. Головченко
}

Молекулярно-генетические детерминанты преэклампсии

Федеральное государственное автономное образовательное учреждение высшего образования «Белгородский государственный национальный исследовательский университет» (НИУ «БелГУ»),

ул. Победы, д. 85, г. Белгород, 308015, Российская Федерация Автор для переписки: O.В. Головченко (gol.doc@mail.ru)

\begin{abstract}
Аннотация
Актуальность: Преэклампсия (ПЭ) продолжает оставаться одним из наиболее тяжелых осложнений беременности. В формирование ПЭ вовлечены молекулярно-генетические факторы. Цель исследования: Изучить вовлеченность полиморфизма rs3798577, rs2234693 и rs9340799 гена ESR1 в формирование преэклампсии. Материалы и методы: Группу для исследования составили 190 беременных с ПЭ и 324 женщины с физиологическим течением беременности (контрольная группа). Клиническое и клинико-лабораторное обследование беременных проводилось на сроке родоразрешения в Перинатальном центре областной клинической больницы Святителя Иоасафа г.Белгорода. Генотипирование полиморфных локусов rs3798577, rs2234693 и rs9340799 гена ESR1 проводилось методом полимеразной цепной реакции синтеза ДНК с использованием соответствующих праймеров и зондов, меченных флюорохромами. Изучение ассоциаций исследуемых генетических маркеров и их эпистатических взаимодействий с развитием ПЭ осуществлялось методом логистической регрессии в программе PLINK v. 2.050. Результаты: Взаимодействие полиморфных вариантов rs9340799 x rs3798577 гена ESRl имеет протективное значение для развития преэклампсии $\left(\mathrm{OR}=0,56, \mathrm{p}=0,004, \mathrm{p}_{\mathrm{bonf}}=0,012\right)$. Данные полиморфные локусы и сильно сцепленные $\left(\mathrm{r}^{2} \geq 0,8\right)$ c rs9340799 шесть SNPs имеют значимые регуляторные эффекты: находятся в области более 20 регуляторных мотивов ДНК к факторам транскрипции Foxa, Foxd1, Foxf2, Foxj1, Foxk, Foxo, HDAC2, Sox, TCF12, p300 и др., локализованы в локусах ДНК, взаимодействующих с регуляторными белками (NRSF, SIN3AK20, TCF12), расположены в регионе модифицированных гистонов, маркирующих энхансеры и промоторы, регионе гиперчувствительности к ДНКазе 1 в более 30 различных культурах клеток, тканях и органах, патогенетически значимых для развития ПЭ. Заключение: Эпистатическое взаимодействие полиморфных локусов rs9340799 x rs3798577 гена ESRI ассоциировано с развитием ПЭ.
\end{abstract}

Ключевые слова: полиморфизм; ассоциации; SNP×SNP взаимодействия; преэклампсия

Для цитирования: Головченко ОВ. Молекулярно-генетические детерминанты преэклампсии. Научные результаты биомедицинских исследований. 2019;5(4):139-149. DOI: 10.18413/2658-6533-2019-5-4-0-11 


\title{
\begin{tabular}{l|l} 
Oleg V. Golovchenko & Molecular genetic determinants of pre-eclampsia
\end{tabular}
}

\author{
Belgorod State National Research University, \\ 85 Pobedy St., Belgorod, 308015, Russia \\ Corresponding author: Oleg V. Golovchenko (gol.doc@mail.ru)
}

\begin{abstract}
Background: Pre-eclampsia (PE) is still one of the most severe complications of pregnancy. Molecular genetic factors are involved in the formation of PE. The aim of the study: To study the involvement of rs3798577, rs2234693 and rs9340799 polymorphisms of the ESR1 gene in the development of preeclampsia. Materials and methods: The studied group consisted of 190 pregnant women with PE and 324 women with physiological pregnancy (control group). The clinical study and clinical laboratory examination of pregnant women were carried out at the time of delivery in the Perinatal Center of the St. Joasaph Regional Clinical Hospital, Belgorod. The polymorphic loci rs3798577, rs2234693 and rs9340799 of the ESR1 gene were genotyped using the polymerase chain reaction of DNA synthesis using the corresponding primers and probes labeled with fluorochromes. The study of associations of the studied genetic markers and their epistatic interactions with the development of PE was carried out by the method of logistic regression in the program PLINK V. 2.050. Results: The interaction of polymorphic variants of rs9340799 x rs3798577 of the ESR1 gene is protective for the development of preeclampsia $(\mathrm{OR}=0.56, \mathrm{p}=0.004$, pbonf $=0.012)$. These polymorphic loci and strongly coupled $(\mathrm{r} 2 \geq 0.8)$ with rs9340799 six SNPs have significant regulatory effects: they are in the region of more than 20 regulatory DNA motifs to transcription factors Foxa, Foxd1, Foxf2, Foxj1, Foxk, Foxo, HDAC2, Sox, TCF12, p300, etc., localized in DNA loci interacting with regulatory proteins (NRSF, SIN3AK20, TCF12), are located in the region of modified histones marking enhancers and promoters, the region of hypersensitivity to DNase 1 in more than 30 different cell cultures, tissues and organs pathogenetically significant for the development of PE. Conclusion: Epistatic interaction of polymorphic loci rs9340799 x rs3798577 of ESR1 gene is associated with the development of PE.
\end{abstract}

Keywords: polymorphism; associations; $\mathrm{SNP} \times \mathrm{SNP}$ interactions; pre-eclampsia

For citation: Golovchenko OV. Molecular genetic determinants of pre-eclampsia. Research Results in Biomedicine. 2019;5(4):139-149. (In Russian) DOI: 10.18413/2658-6533-2019-5-4-0-11

Введение. Одним из наиболее тяжелых осложнений беременности до настоящего времени остается преэклампсия (ПЭ) $[1,2]$. Ежегодно около 40000 рожениц могут умереть из-за преэклампсии и эклампсии [3]. У новорожденных, родившихся у матерей с преэклампсией чаще выявляются врожденные аномалии развития и генетическая патология, отмечаются метаболические нарушения, выше риск инфекционных состояний и гематологических нарушений [4]. Причем тяжесть состояния новорожденных, риск неонатальных осложнений, тяжесть течения инфекционных процессов, гипоксическиишемических состояний имеют прямую корреляционную зависимость от сроков возникновения и тяжести преэклампсии [4].

Несмотря на многочисленные проведенные исследования ПЭ различными как отечественными, так и зарубежными научными коллективами данное 
осложнение беременности остается одной из актуальных нерешенных научнопрактических проблем в мировом акушерстве. Сложные многофакторные механизмы развития ПЭ, известные к настоящему времени (эндотелиальная дисфункция, глубокие расстройства со стороны сосудистой системы, гемодинамики и микроциркуляции, иммунитета, гемостаза, плацентарная недостаточность, аномальная активация белков системы комплемента с развитием тромботической микроангиопатии, различные нарушения функции печени, почек, легких и др.) [5-8], предполагающие вовлеченность в ее формирование различных факторов риска (генетических, экологических, медицинских, социальных и др.) [1, 8-10] не позволяют дать однозначного ответа о причинах развития ПЭ и соответственно предложить эффективные меры ее профилактики. Одним из перспективных маркеров которые могут быть использованы для формирования среди женщин группы риска по развитию ПЭ являются молекулярно-генетические маркеры [9-14]. Использование генетических детерминант в качестве эффективных маркеров для выделения группы риска по развитию ПЭ определяется их вовлеченностью в этиопатогенез этого осложнения беременности. При этом следует учитывать что наиболее эффективное значение в выделении группы риска эти маркеры будут иметь в тех этно-территориальных группах женщин, для которых установлена их значимая роль в развитии ПЭ. Поэтому одной из актульных задач современных исследований в области акушерства является поиск молекулярно-генетических маркеров генов-кандидатов, ассоциированных с развитием ПЭ в различных этнических и территориальных группах, которые в последующем можно было бы использовать в практическом здравоохранении для формирования среди женщин группы риска по развитию ПЭ в прегравидарный период или в ранние сроки беременности и реализации мероприятий по профилактике этого осложнения беременности в этих группах риска.

Цель исследования. Изучить вовлеченность полиморфизма rs3798577, rs2234693 и rs9340799 гена ESRI в формирование преэклампсии.

\section{Материалы и методы исследова-}

ния. Группу для исследования составили 190 беременных с ПЭ и 324 женщины с физиологическим течением беременности (контрольная группа). Общий объем исследуемой выборки составил 514 женщин. В работу включались (критерии включения) индивидуумы русской национальности, проживающие в Белгородской области, родившиеся в Центральном Черноземье России, не являющиеся родственниками. Критерии исключения из исследуемых выборок: наличие заболеваний матки (фибромиома матки, аномалии развития внутренних половых органов), патологии беременности (аномалии прикрепления и расположения плаценты, резус-конфликт, плацентарная недостаточность с синдромом задержки развития плода), патологии плода (врожденные аномалии развития), многоплодной беременности.

Диагноз ПЭ ставился на основании наличия генерализованных отеков, артериальной гипертензии и протеинурии. В контрольную группу включались беременные без диагноза ПЭ. Клиническое и клиниколабораторное обследование беременных проводилось на сроке родоразрешения в Перинатальном центре областной клинической больницы Святителя Иоасафа г.Белгорода. Выборки формировались за период с 2008 по 2015гг. Средний возраст беременных с ПЭ составил 26,88 $\pm 5,37$ лет, контрольной группы - 26,27士4,88 (p>0,05). Исследование проводилось под контролем этического комитета медицинского института Белгородского государственного национального исследовательского университета. От каждой женщины, включенной в исследование, предварительно было получено информированное согласие на его проведение.

В исследуемых группах женщин (с ПЭ и контрольная группа) проведено мо- 
лекулярно-генетическое исследование трех полиморфных локусов гена рецептора эстрогена 1 типа - rs3798577, rs2234693 и rs9340799 ESR1. Полиморфные локусы включались в исследование в соответствии с их значимым регуляторным потенциалом. Генотипирование проводилось методом полимеразной цепной реакции синтеза ДНК с использованием соответствующих праймеров и зондов, меченных флюорохромами.

Сравнение частот генетических маркеров между беременными с ПЭ и контрольной группой производилось в таблицах сопряженности 2х2 в программном обеспечении «STATISTICA for Windows $6.0 »$. Изучение ассоциаций исследуемых генетических маркеров и их эпистатических взаимодействий с развитием ПЭ осуществлялось методом логистической регрессии в программе PLINK v. 2.050 (http://zzz.bwh.harvard.edu/plink/).

Функциональное значение рассматриваемых полиморфных локусов и сильно сцепленных с ними SNPs $\left(r^{2} \geq 0,8\right)$ изучалось с помощью программы HaploReg (v4.1)

(http://archive.broadinstitute.org/mammals/ha ploreg/haploreg.php).

Результаты и их обсуждение. Проведенный анализ наблюдаемого распределения генотипов по полиморфным локусам rs3798577, rs2234693 и rs9340799 гена ESRl среди беременных с ПЭ и в контрольной группе показал его соответствие ожидаемому распределению согласно равновесия Харди-Вайнберга ( (таблица 1). Достоверных различий в частотах аллелей и генотипов по изучаемым полиморфизмам у беременных с ПЭ и в контрольной группе не выявлено ( $>0,05)$ (таблица 1).

На следующем этапе исследования нами были изучены SNPxSNP взаимодействия, ассоциированные с развитием ПЭ. В результате этого анализа установлено статистически значимое эпистатическое вза- имодействие полиморфных локусов rs9340799 x rs3798577 (OR=0,56, p=0,004, c учетом поправки Бонферрони на количество возможных двух-локусных моделей с участием 3 SNPs $\mathrm{p}_{\mathrm{bonf}}=0,012$ ), ассоциированное с развитием ПЭ. Таким образом, эпистатическое взаимодействие полиморфных вариантов rs9340799 и rs3798577 гена ESRI имеет протективное значение для развития ПЭ.

Далее с помощью биоинформатического программного обеспечения программы HaploReg (v4.1) проведено изучение функционального значения ПЭзначимых полиморфных локусов и сильно сцепленных с ними SNPs. Установлено, что полиморфизм rs3798577, находящийся в регионе 3'-UTR гена ESRI имеет значимый регуляторный потенциал - он расположен в регионе модифицированных гистоновых белков (H3K4me3 и Н3К9ас), маркирующих промоторы в адипоцитах, скелетной мышечной ткани женщин, культуре клеток мышечных сателлитов, культуре мезенхимальных стволовых клеток, предшественников жировой ткани и др. Так же этот полиморфный локус находится в регионе модифицированных гистоновых белков (H3K4me1 и Н3K27ac), маркирующих энхансеры в более 30 различных культурах клеток, тканях и органах (культуре клеток экто-, энто - и мезодермы, Н1 и Н9 культурах клеток, предшественников нейронов, мезенхимальных стволовых клетках, мышечной ткани женщин, в различных органах плода (мышечная ткань, сердце, надпочечники, желудок и др.), адипоцитах, головном мозге, яичниках и др.). Следует отметить, что данный полиморфный локус находится в регионе гистоновых белков, маркирующих энхансеры в таких патогенетически значимых для развития ПЭ провизорных органах как амнион и плацента. Сильно сцепленных SNPs $\left(\mathrm{r}^{2} \geq 0,8\right)$ с полиморфным локусом rs 3798577 нами не установлено. 
Распределение полиморфных вариантов rs3798577, rs2234693 и rs9340799 гена ESRI

Таблица 1 у беременных с ПЭ и в контрольной группе

Table 1

Distribution of polymorphic variants of rs3798577, rs2234693 and rs9340799 of the ESR1 gene in pregnant women with $P E$ and in the control group

\begin{tabular}{|c|c|c|c|c|c|}
\hline 密 & Аллели, генотипы & $\begin{array}{c}\text { ПЭ }(\mathrm{n}=190) \\
\text { абс. }(\%)\end{array}$ & $\begin{array}{c}\text { Контроль }(\mathrm{n}=324) \\
\text { абс. }(\%)\end{array}$ & OR $(95 \% \mathrm{CI})$ & $\mathrm{p}$ \\
\hline \multirow{10}{*}{ 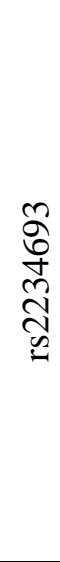 } & $\mathrm{C}$ & $183(49,03 \%)$ & $326(51,58 \%)$ & $0,90(0,69-1,17)$ & \multirow{2}{*}{0,45} \\
\hline & $\mathrm{T}$ & $191(51,07 \%)$ & $306(48,42 \%)$ & $1,11(0,86-1,42)$ & \\
\hline & $\mathrm{C} / \mathrm{C}$ & $44(23,53 \%)$ & $79(25,00 \%)$ & $0,92(0,59-1,44)$ & 0,79 \\
\hline & $\mathrm{C} / \mathrm{T}$ & $95(50,80 \%)$ & $168(53,16 \%)$ & $0,91(0,62-1,33)$ & 0,67 \\
\hline & $\mathrm{T} / \mathrm{T}$ & $48(25,67 \%)$ & $69(21,84 \%)$ & $1,23(0,79-1,93)$ & 0,38 \\
\hline & $\mathrm{H}_{\mathrm{o}} / \mathrm{H}_{\mathrm{e}}$ & $0,51 / 0,50$ & $0,53 / 0,50)$ & & \\
\hline & $\mathrm{P}_{\mathrm{HWE}}$ & 0,88 & 0,31 & & \\
\hline & $\begin{array}{l}\text { C/C vs. C/T vs. T/T (аддитивная } \\
\text { модель) }\end{array}$ & & & $1,12(0,86-1,45)$ & 0,40 \\
\hline & $\begin{array}{l}\mathrm{C} / \mathrm{C} \text { vs. C/T + T/T (доминантная } \\
\text { модель) }\end{array}$ & & & $1,08(0,71-1,65)$ & 0,71 \\
\hline & $\begin{array}{l}\text { C/C + C/T vs. T/T (рецессивная } \\
\text { модель) }\end{array}$ & & & $1,23(0,81-1,89)$ & 0,32 \\
\hline \multirow{10}{*}{ 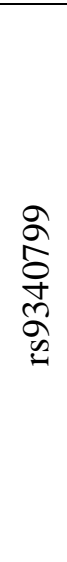 } & $\mathrm{A}$ & $233(63,63 \%)$ & $389(61,16 \%)$ & $1,06(0,81-1,40)$ & \multirow{2}{*}{0,69} \\
\hline & $\mathrm{G}$ & $139(37,37 \%)$ & $247(38,84 \%)$ & $0,93(0,72-1,22)$ & \\
\hline & $\mathrm{A} / \mathrm{A}$ & $75(40,32 \%)$ & $119(37,42 \%)$ & $1,13(0,77-1,66)$ & 0,58 \\
\hline & $\mathrm{A} / \mathrm{G}$ & $83(44,62 \%)$ & $151(47,48 \%)$ & $0,89(0,61-1,30)$ & 0,60 \\
\hline & $\mathrm{G} / \mathrm{G}$ & $28(15,06 \%)$ & $48(15,10 \%)$ & $0,99(0,58-1,70)$ & 1,00 \\
\hline & $\mathrm{H}_{\mathrm{o}} / \mathrm{H}_{\mathrm{e}}$ & $0,45 / 0,47$ & $0,47 / 0,47)$ & & \\
\hline & $P_{\text {HWE }}$ & 0,53 & 1,00 & & \\
\hline & $\begin{array}{l}\text { A/A vs. A/G vs. G/G (аддитивная } \\
\text { модель) }\end{array}$ & & & $0,94(0,72-1,22)$ & 0,65 \\
\hline & $\begin{array}{l}\text { A/A vs. A/G + G/G (доминантная } \\
\text { модель) }\end{array}$ & & & $0,88(0,61-1,28)$ & 0,52 \\
\hline & $\begin{array}{l}\text { A/A + A/G vs. G/G (рецессивная } \\
\text { модель) }\end{array}$ & & & $0,99(0,60-1,65)$ & 0,99 \\
\hline \multirow{10}{*}{$\begin{array}{l}\hat{\sigma} \\
\infty \\
\infty \\
\hat{\sigma} \\
\hat{n}\end{array}$} & $\mathrm{C}$ & $200(52,91 \%)$ & $342(52,78 \%)$ & $1,00(0,77-1,31)$ & \multirow{2}{*}{0,96} \\
\hline & $\mathrm{T}$ & $178(47,09 \%)$ & $306(47,22 \%)$ & $0,99(0,77-1,28)$ & \\
\hline & $\mathrm{C} / \mathrm{C}$ & $57(30,16 \%)$ & $94(29,01 \%)$ & $1,06(0,70-1,59)$ & 0,86 \\
\hline & $\mathrm{C} / \mathrm{T}$ & $86(45,50 \%)$ & $154(47,53 \%)$ & $0,92(0,63-1,34)$ & 0,72 \\
\hline & $\mathrm{T} / \mathrm{T}$ & $46(24,34 \%)$ & $76(23,46 \%)$ & $1,05(0,67-1,63)$ & 0,91 \\
\hline & $\mathrm{H}_{\mathrm{o}} / \mathrm{H}_{\mathrm{e}}$ & $0,45 / 0,49$ & $0,47 / 0,50)$ & & \\
\hline & $P_{\text {HWE }}$ & 0,24 & 0,43 & & \\
\hline & $\begin{array}{l}\text { C/C vs. C/T vs. T/T (аддитивная } \\
\text { модель) }\end{array}$ & & & $0,99(0,78-1,27)$ & 0,97 \\
\hline & $\begin{array}{l}\text { C/C vs. C/T + T/T (доминантная } \\
\text { модель) }\end{array}$ & & & $0,94(0,64-1,40)$ & 0,78 \\
\hline & $\begin{array}{l}\text { C/C + C/T vs. T/T (рецессивная } \\
\text { модель) }\end{array}$ & & & $1,05(0,69-1,60)$ & 0,82 \\
\hline
\end{tabular}

Примечание: $\mathrm{H}_{\mathrm{o}}$ - наблюдаемая гетерозиготность, $\mathrm{H}_{\mathrm{e}}$ - ожидаемая гетерозиготность, $\mathrm{P}_{\text {нwе }}$ - показатель, характеризующий соответствие наблюдаемого распределения генотипов ожидаемому при равновесии Харди-Вайнберга, OR - показатель отношения шансов, 95\% СI -его 95\% доверительный интервал, $\mathrm{p}$ - уровень значимости.

Note: $\mathrm{H}_{\mathrm{o}}$ - the observed heterozygosity, $\mathrm{H}_{\mathrm{e}}$ - expected heterozygosity, $\mathrm{P}_{\mathrm{HWE}}-$ an indicator characterizing the correspondence of the observed distribution of genotypes to the expected one at Hardy-Weinberg equilibrium, OR the odds ratio indicator, $95 \% \mathrm{CI}$ - its $95 \%$ confidence interval, $\mathrm{p}$ - the significance level. 
Результаты изучения функционального значения полиморфизма rs9340799 гена ESRI и сильно сцепленных с ним 6 SNPs $\left(\mathrm{r}^{2} \geq 0,8\right)$ представлены в таблице 2 . Полученные данные свидетельствуют о том, что ПЭ-ассоциированный rs9340799 (локализуется в интронном участке гена ESRl) находится в консервативном регионе ДНК и входит в состав двух регуляторных мотивов ДНК (Ets, Hand1). Причем полиморфный вариант G rs9340799 повышает афинность обоих этих регуляторных мотивов ДНК. Среди сильно сцепленных с ним полиморфных локусов $\left(\mathrm{r}^{2} \geq 0,8\right)$ наиболее важное регуляторное значение имеет rs62442056 (находится на расстоянии $5 \mathrm{~kb}$ от полиморфизма rs $9340799, \mathrm{r}^{2}=0,94, \mathrm{D}^{\prime}=1$ ) - он находится в регионе гиперчувствительности к ДНКазе 1 в 29 различных культурах клеток, тканях и органах (культуре клеток экто-, энто- и мезодермы, мезенхимальных стволовых клетках, мышечной ткани женщин, адипоцитах, головном мозге, яичниках, в различных органах плода (головной мозг плода женского пола, мышечная ткань, сердце, надпочечники и др.), амнионе и плаценте и др.), области ДНК, взаимодействующей с тремя регуляторными белками (NRSF, SIN3AK20, TCF12), регионе 5 регуляторных мотивов ДНК, влияющего на афинность к транскрипционным факторам (CEBPB, Foха, Foxi1, HDAC2, TCF12). Так же выраженный регуляторный потенциал имеет находящийся в неравновесии по сцеплению с rs9340799 полиморфный локус rs3853251 (находится на расстоянии 2,6 kb от полиморфизма rs9340799, $\left.\mathrm{r}^{2}=0,94, \mathrm{D}^{\prime}=1\right)$. Данный полиморфизм находится в регионе 10 регуляторных мотивов, влияющих на связывание ДНК с транскрипционными факторами Foxa, Foxd1, Foxf2, Foxj1, Foxk, Foxo, HDAC2, Sox, TCF12, p300).

Согласно данных базы GeneCards: The Human Gene Database (http://www.genecards.org/) ген ESRl кодирует alpha-рецепторы эстрогенов. Данные рецепторы являются трансмембранным белком, в котором С-конец является центром связывания с лигандом, N-конец включает ряд доменов, регулирующих транскрипционную активность ряда генов. Рецепторы эстрогенов (ESR1) потенцируют как различные биологические эффекты эстрогенов в клетках мишенях так и могут активироваться различными факторами роста, инициируя ядерно-ER-опосредованные сигнальные пути, основными из которых являются сигнальные каскады рецептора к тирозинкиназе (RTKs), сигналрегулируемых внеклеточных киназ (ERK), митоген-активированных протеинкиназ (MAPK) и др. [15], что может иметь важное патогенетическое значение при формировании ПЭ [1-2, 9]. Полученные нами данные согласуются с литературными материалами по этому вопросу. В 2019 г опубликована работа Zhao G. et al. [3], посвященная мета-анализу результатов научных исследований ассоциаций полиморфных локусов rs2234693 (PvuII-397T/C) и rs9340799 (XbaI-351A/G) с формированием преэклампсии легкой и тяжелой степени. Мета-анализ был проведен по материалам 6 работ, представленных в базах данных PubMed, Medline, Embase, China National Knowledge Infrastructure (CNKI) и WanFang до мая 2018 года. Авторы установили, что повышенный риск развития тяжелой преэклампсии связан с полиморфизмом XbaI$351 \mathrm{~A} / \mathrm{G}(\mathrm{OR}=1,67,95 \% \mathrm{CI}=1,10-2,25$, $\mathrm{P}=0,017$ для $\mathrm{GG}$ по сравнению с $\mathrm{AA}+\mathrm{GA}$; $\mathrm{OR}=1,81,95 \% \mathrm{CI}=1,17-2,82, \mathrm{P}=0,008$ для GG по сравнению с GA).

На основании полученных данных авторы делают вывод о том, что генотип GG полиморфизма XbaI (rs9340799) гена ESR1 может быть генетическим фактором риска развития тяжелой преэклампсии. Наряду с этим полиморфизм PvuII-397T/C (rs2234693) гена ESR1 не был достоверно связан с риском развития тяжелой преэклампсии. 
Функциональное значение полиморфизма rs9340799 гена $E S R 1$ и сильно сцепленных с ними $\operatorname{SNPs}\left(\mathrm{r}^{2} \geq 0,8\right)$ (по данным программы HaploReg (v4.1) (http://archive.broadinstitute.org/mammals/haploreg/haploreg.php))

The functional significance of rs9340799 polymorphism of the ESR1 gene and SNPs strongly linked to them (r2 $\geq 0.8)$

(according to the program HaploReg (v4.1) (http://archive.broadinstitute.org/mammals/haploreg/haploreg.php))

\begin{tabular}{|c|c|c|c|c|c|c|c|c|c|c|c|c|c|}
\hline pos (hg38) & $\mathrm{r}^{2}$ & $D^{\prime}$ & SNP & Ref & Alt & AFR & AMR & ASN & EUR & GERP & DNAse & Proteins & Motifs \\
\hline 151788487 & 0,81 & 0,91 & rs145387702 & CTT & $\mathrm{C}$ & 0,06 & 0,21 & 0,07 & 0,28 & & & & $\begin{array}{c}4 \text { altered } \\
\text { motifs }\end{array}$ \\
\hline 151839621 & 0,94 & 1 & rs3853251 & A & $\mathrm{G}$ & 0,11 & 0,26 & 0,02 & 0,28 & & & & $\begin{array}{l}10 \text { altered } \\
\text { motifs }\end{array}$ \\
\hline 151841182 & 0,94 & 1 & rs9322331 & $\mathrm{C}$ & $\mathrm{T}$ & 0,11 & 0,25 & 0,02 & 0,28 & & & & \\
\hline 151842246 & 1 & 1 & rs9340799 & A & G & 0,27 & 0,29 & 0,18 & 0,29 & & & & $\begin{array}{c}2 \text { altered } \\
\text { motifs }\end{array}$ \\
\hline 151846176 & 0,94 & 1 & rs3936674 & G & A & 0,07 & 0,24 & 0,02 & 0,28 & & & & $\begin{array}{c}4 \text { altered } \\
\text { motifs }\end{array}$ \\
\hline 151847311 & 0,94 & 1 & rs62442056 & A & $\mathrm{T}$ & 0,05 & 0,24 & 0,02 & 0,28 & & 29 tissues & 3 proteins & $\begin{array}{c}5 \text { altered } \\
\text { motifs }\end{array}$ \\
\hline 151850763 & 0,8 & 0,92 & rs4870057 & A & G & 0,2 & 0,25 & 0,02 & 0,28 & & 2 tissues & & $\begin{array}{c}2 \text { altered } \\
\text { motifs }\end{array}$ \\
\hline
\end{tabular}

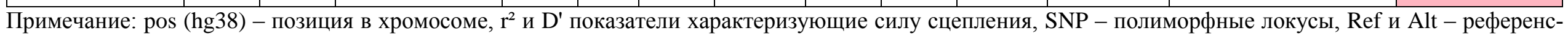

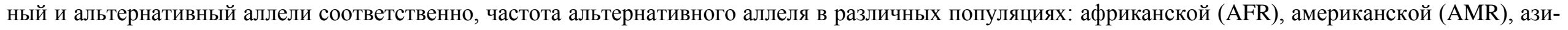

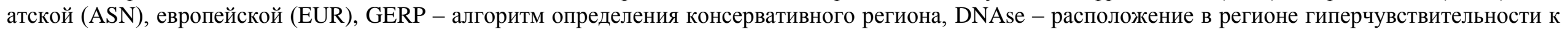

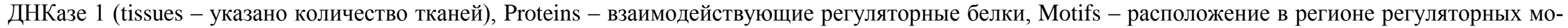
тивов ДНК (altered motifs - указано количество регуляторных мотивов ДНК).

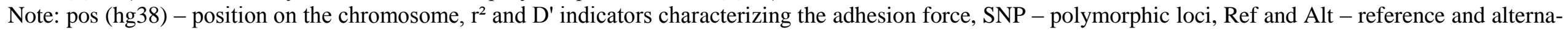

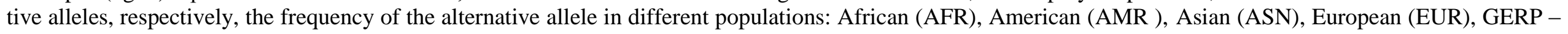

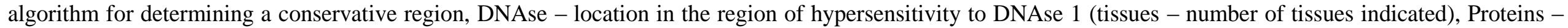
interacting regulatory proteins, Motifs - location in the region of regulatory motifs of DNA (altered motifs - the number of regulatory DNA motifs is indicated). 
Также не установлено значимых ассоциаций между преэклампсией легкой степени и полиморфизмами PvuII-397T/C и $\mathrm{XbaI}-351 \mathrm{~A} / \mathrm{G}$ гена ESR1. В ряде работ показана вовлеченность полиморфных локусов гена ESRI в формирование такого важного показателя, характеризующего функционирование гипоталамо-гипофизарнояичниковой системы женщины, как возраст менархе $[16,17]$ и развитие различных нарушений репродуктивной системы женщин (повторные самопроизвольные аборты, бесплодие, рак молочной железы, синдром поликистозных яичников и др.) [18-21]. Следует отметить, что наши результаты дополняют полученные ранее данные о значимой роли молекулярно-генетических факторов в формировании нарушений репродуктивного здоровья женщин Центрального Черноземья России [22-28].

Заключение. Эпистатическое взаимодействие rs9340799 х rs3798577 гена ESR1 ассоциировано с развитием преэклампсии $\left(\mathrm{OR}=0,56, \mathrm{p}_{\mathrm{bonf}}=0,012\right)$. Данные полиморфные локусы и сильно сцепленные $\left(\mathrm{r}^{2} \geq 0,8\right)$ с rs9340799 шесть SNPs имеют значимые регуляторные эффекты: находятся в области более 20 регуляторных мотивов ДНК, расположены в регионе модифицированных гистонов, маркирующих энхансеры и промоторы, регионе гиперчувствительности к ДНКазе 1 в более 30 различных культурах клеток, тканях и органах, патогенетически значимых для развития ПЭ.

В отношении данной статьи не было зарегистрировано конфликта интеpecoв.

\section{Список литературы}

1. Сидорова И.С. Решенные вопросы и нерешенные проблемы преэклампсии в России // Российский вестник акушера-гинеколога. 2015. $\begin{array}{llll}\text { T. } 5, & \text { N } 2 . & \text { C. } 4 \text {. } & \text { DOI: }\end{array}$ 10.17116/rosakush20151524-9

2. Акушерские и перинатальные осложнения у юных первородящих / В.Е. Радзинский [и др.] // Доктор.Ру. 2019. N 7(162). C. 6-11. DOI: 10.31550/1727-2378-2019-162-7-6-11

3. Association between the estrogen receptor $\alpha$ gene polymorphisms rs2234693 and rs9340799 and severe and mild pre-eclampsia: a meta-analysis / G. Zhao [et al.] // Biosci Rep. 2019. Vol. 39(2). P. BSR20181548. DOI:10.1042/BSR20181548

4. Роль преэклампсии в исходах беременности: взгляд неонатолога / Л.А. Тимофеева [и др.] // Акушерство и гинекология. 2019. N 4. C. 73-8.

DOI: https://dx.doi.org/10.18565/aig.2019.4.73-78

5. Pre-eclampsia part 1: current understanding of its pathophysiology / T. Chaiworapongsa [et al.] // Nat Rev Nephrol. 2014;10(8):466-480. DOI: 10.1038/nrneph.2014.102

6. Association of pre-eclampsia risk with maternal levels of folate, homocysteine and vitamin B12 in Colombia: A case-control study / N.C. Serrano [et al.] // PLoS One. 2018;13(12):e0208137. DOI: 10.1371/journal.pone.0208137

7. Сидорова И.С., Никитина Н.А. Обоснование современной концепции развития преэклампсии // Акушерство и гинекология. 2019. $\mathrm{N} 4$. C. 26-33.

DOI: https://dx.doi.org/10.18565/aig.2019.4.26-33

8. Endothelial dysfunction in the pathogenesis of pre-eclampsia in Ghanaian women / K. AduBonsaffoh [et al.] // BMC Physiol. 2017. Vol. 17(1). P. 5. DOI: 10.1186/s12899-017-0029-4

9. Фролова Н.И., Белокриницкая Т.Е., Колмакова К.А. Молекулярные маркеры и эпигенетические факторы риска преэклампсии в эпоху предиктивной медицины // Вопросы гинекологии, акушерства и перинатологии. 2019. T. 18 , N 4. C. $95-103$. DOI: $10.20953 / 1726-1678-$ 2019-4-95-103

10.Zhao L., Bracken M.B., DeWan A.T. Genome-wide association study of pre-eclampsia detects novel maternal single nucleotide polymorphisms and copy-number variants in subsets of the Hyperglycemia and Adverse Pregnancy Outcome (HAPO) study cohort // Ann Hum Genet. 2013. Vol. 77(4). P. 277-287. DOI: 10.1111/ahg.12021

11. Сереброва В.Н., Трифонова Е.А., Степанов В.А. Эволюционно-генетический анализ роли регуляторных участков гена CORO2A в формировании наследственной предрасположенности к преэклампсии у русских и якутов // Научные результаты биомедицинских исследований. 2018. T. 4, N 3. С. 38-48. DOI: 10.18413/2313-8955-2018-4-3-0-4.

12. Роль полиморфизма регуляторных регионов гена VEGF-A в предрасположенности к развитию преэклампсии / Л.В. Акуленко [и др.] // Вопросы гинекологии, акушерства и перинатологии. 2018. Т. 17, N 1. С. 22-6. DOI: 10.20953/1726-1678-2018-1-22-26 
13. Генетические предикторы преэклампсии / С.Г. Цахилова [и др.] // Проблемы репродукции. 2017. Т. 23, N 1. C. 110-114. DOI: 10.17116/repro2017231110-114

14. Genome-wide association scan identifies a risk locus for preeclampsia on $2 \mathrm{q} 14$, near the inhibin, beta B gene / M.P. Johnson [et al.] // PLoS One. 2012. Vol. 7(3). P. e33666. DOI: 10.1371/journal.pone.0033666

15.Plant T.M. The hypothalamo-pituitarygonadal axis // The Journal of endocrinology. 2015. Vol. 226(2). P. T41-T54. DOI: 10.1530/JOE-150113

16. Genome-wide association studies and epistasis analyses of candidate genes related to age at menarche and age at natural menopause in a Korean population / J.A. Pyun [et al.] // Menopause. 2014. Vol. 21(5). P. 522-9. DOI: 10.1097/GME.0b013e3182a433f7

17. Полиморфизм гена ESRI ассоциирован с возрастом менархе у женщин России / И.В. Пономаренко [и др.] // Вопросы гинекологии, акушерства и перинатологии. 2019. Т. 18, N 5. С. 29-34. DOI: 10.20953/1726-1678-2019-5-29-34

18. Association of Estrogen Receptor $1 \mathrm{Ge}-$ netic Polymorphisms with Recurrent Spontaneous Abortion Risk / X.Q. Yin [et al.] // Chin Med J (Engl). 2018. Vol. 131(15). P. 1857-1865. DOI: 10.4103/0366-6999.237412

19. Polymorphism analysis in estrogen receptors alpha and beta genes and their association with infertile population in Pakistan / S. Liaqat [et al.] // EXCLI J. 2015. N 14. P. 1085-1094. DOI: 10.17179/excli2015-559

20. Genetic polymorphisms of estrogen receptor genes are associated with breast cancer susceptibility in Chinese women / Z. Dai [et al.] // Cancer Cell Int. 2019. N 19. P. 11. DOI: 10.1186/s12935019-0727-z

21. Variant Alleles of the ESRl, PPARG, HMGA2, and MTHFR Genes Are Associated With Polycystic Ovary Syndrome Risk in a Chinese Population: A Case-Control Study / X. Jiao [et al.] // Front Endocrinol (Lausanne). 2018. N 9. P. 504. DOI: 10.3389/fendo.2018.00504

22. Пономаренко И.В., Полоников А.В., Чурносов М.И. Полиморфные локусы гена LHCGR, ассоциированные с развитием миомы матки // Акушерство и гинекология. 2018. N 10. C. 86-91. DOI: 10.18565/aig.2018.10.86-91

23. Genetic factors of hysteromyoma / I.V. Krivoshei [et al.] // Research Journal of Medical Sciences. 2015. Vol. 9(4). P. 182-185. DOI: $10.36478 /$ rjmsci.2015.182.185
24. Associations of cytokines genetic variants with myomatous knots sizes / M.I. Churnosov [et al.] // Research Journal of Pharmaceutical, Biological and Chemical Sciences. 2014. Vol. 5(6). P. 1344-1347.

25.Изучение роли индекса массы тела в характере ассоциаций генетических полиморфизмов вазоактивных гормонов с показателями артериального давления у женщин в конце беременности / Е.А. Решетников [и др.] // Научные ведомости Белгородского государственного университета. Серия: Медицина. Фармация. 2011. N 4(99). C. 153-159.

26. Bioinformatic analysis of the liability to the hyperplastic processes of the uterus / I.V. Krivoshei [et al.] // Research Journal of Pharmaceutical, Biological and Chemical Sciences. 2015. Vol. 6(5). C. 1563-1566.

27. Полиморфный локус rs314276 гена LIN28B ассоциирован с возрастом менархе у женщин Центрального Черноземья России / И.В. Пономаренко [и др.] // Акушерство и гинекология. 2019. $\mathrm{N} \quad 2 . \quad$ C. 98-104. DOI: 10.18565/aig.2019.2.98-104

28. Ассоциации генетического полиморфизма ангиотензин-конвертирующего фермента с показателями артериального давления у беременных в зависимости от индекса массы тела / Е.А. Решетникова [и др.] // Научные ведомости Белгородского государственного университета. Серия: Медицина. Фармация. 2016. N 19(240). C. 89-95.

\section{References}

1. Sidorova IS. [Solutions and unsolved problems of preeclampsia in Russia]. Rossiyskiy vestnik akushera-ginekologa. 2015;5(2):4-9. Russian. DOI: 10.17116/rosakush20151524-9

2. Radzinsky VE, Khamoshina MB, Chakchurina IA, et al. [Obstetrical and Perinatal Complications in Young Primiparas]. Doctor.Ru. 2019;7(162):6-11. Russian. DOI: 10.31550/17272378-2019-162-7-6-11

3. Zhao G, Cai Y, Liu J, et al. Association between the estrogen receptor $\alpha$ gene polymorphisms rs2234693 and rs9340799 and severe and mild pre-eclampsia: a meta-analysis. Biosci Rep. 2019;39(2):BSR20181548.

DOI:10.1042/BSR20181548

4. Timofeeva LA, Karavaeva AL, Zubkov $\mathrm{V}$, et al. [The role of preeclampsia in pregnancy outcomes: the view of a neonatologist]. Akusherstvo i ginekologiya. 2019;4:73-8. Rus- 
sian.

DOI:

https://dx.doi.org/10.18565/aig.2019.4.73-78

5. Chaiworapongsa $\mathrm{T}$, Chaemsaithong $\mathrm{P}$, Yeo L, et al. Pre-eclampsia part 1: current understanding of its pathophysiology. Nat Rev Nephrol. 2014;10(8):466-480. DOI: 10.1038/nrneph.2014.102

6. Serrano NC, Quintero-Lesmes DC, Becerra-Bayona $\mathrm{S}$, et al. Association of pre-eclampsia risk with maternal levels of folate, homocysteine and vitamin B12 in Colombia: A case-control study. PLoS One. 2018;13(12):e0208137. DOI: 10.1371/journal.pone.0208137

7. Sidorova IS, Nikitina NA. [Justification of the modern concept of the development of preeclampsia]. Akusherstvo i ginekologiya. 2019;4:26-33. Russian. DOI: https://dx.doi.org/10.18565/aig.2019.4.26-33

8. Adu-Bonsaffoh K, Antwi DA, Gyan B, et al. Endothelial dysfunction in the pathogenesis of pre-eclampsia in Ghanaian women. BMC Physiol. 2017;17(1):5. DOI: 10.1186/s12899-017-0029-4

9. Frolova NI, Belokrinitskaya TE, Kolmakova KA. [Molecular markers and epigenetic risk factors for preeclampsia in the era of predictive medicine]. Gynecology, Obstetrics and Perinatology. 2019;8(4):95-103. Russian. DOI: 10.20953 / 1726-1678-2019-4-95-103

10.Zhao L, Bracken MB, DeWan AT. Genome-wide association study of pre-eclampsia detects novel maternal single nucleotide polymorphisms and copy-number variants in subsets of the Hyperglycemia and Adverse Pregnancy Outcome (HAPO) study cohort. Ann Hum Genet. 2013;77(4):277-287. DOI:10.1111/ahg.12021

11.Serebrova VN, Trifonova EA, Stepanov VA. [Evolutionary-genetic analysis of the role of regulatory regions in CORO2A gene in the development of hereditary predisposition to preeclampsia in Russians and Yakuts]. Research Results in Biomedicine. 2018;4(3):38-48. Russian. DOI: 10.18413/2313-8955-2018-4-3-0-4

12. Akulenko LV, Kuznetsov VM, Tsakhilova SG, et al. [The role of VEGF-A gene regulatory region polymorphism in predisposition to the development of preeclampsia]. Gynecology, Obstetrics and Perinatology. 2018;17(1):22-6. Russian. DOI: 10.20953 / 1726-1678-2018-1-2226

13. Tsakhilova SG, Akulenko LV, Kuznetsov VM, et al. [Genetic predictors of preeclampsia]. Reproduction problems. 2017;23(1):110-114. Russian. DOI: 10.17116 / repro2017231110-114
14.Johnson MP, Brennecke SP, East CE, et al. Genome-wide association scan identifies a risk locus for preeclampsia on $2 \mathrm{q} 14$, near the inhibin, beta B gene. PLoS One. 2012;7(3):e33666. DOI: 10.1371/journal.pone.0033666

15.Plant TM. The hypothalamo-pituitarygonadal axis. The Journal of endocrinology. 2015;226(2):T41-T54. DOI: 10.1530/JOE-15-0113

16. Pyun JA, Kim S, Cho NH, et al. Genomewide association studies and epistasis analyses of candidate genes related to age at menarche and age at natural menopause in a Korean population. Menopause. $2014 \quad$ May;21(5):522-9. DOI: 10.1097/GME.0b013e3182a433f7

17.Ponomarenko IV, Reshetnikov EA, Polonikov AV, et al. [ESR1 gene polymorphism is associated with menarche age in Russian women]. Gynecology, Obstetrics and Perinatology. 2019;18(5):29-34. Russian. DOI: 10.20953 / 1726-1678-2019-5-29-34

18. Yin XQ, Ju HM, Guo Q, et al. Association of Estrogen Receptor 1 Genetic Polymorphisms with Recurrent Spontaneous Abortion Risk. Chin Med J (Engl). 2018;131(15):1857-1865. DOI: 10.4103/0366-6999.237412

19.Liaqat S, Hasnain S, Muzammil S, et al. Polymorphism analysis in estrogen receptors alpha and beta genes and their association with infertile population in Pakistan. EXCLI J. 2015;14:10851094. DOI: $10.17179 /$ excli2015-559

20.Dai Z, Tian T, Wang M, et al. Genetic polymorphisms of estrogen receptor genes are associated with breast cancer susceptibility in Chinese women. Cancer Cell Int. 2019;19:11. DOI: 10.1186/s12935-019-0727-z

21.Jiao X, Chen W, Zhang J, et al. Variant Alleles of the ESR1, PPARG, HMGA2, and MTHFR Genes Are Associated With Polycystic Ovary Syndrome Risk in a Chinese Population: A CaseControl Study. Front Endocrinol (Lausanne). 2018;9:504. DOI: 10.3389/fendo.2018.00504

22. Ponomarenko IV, Polonikov AV, Churnosov MI. [Polymorphic loci of the LHCGR gene associated with the development of uterine fibroids]. Akusherstvo i ginekologiya. 2018;10:86-91. Russian. DOI: 10.18565 / aig.2018.10.86-91

23. Krivoshei IV, Altuchova OB, Golovchenko OV, et al. Genetic factors of hysteromyoma. Research Journal of Medical Sciences. 2015;9(4):182185. DOI: $10.36478 /$ rjmsci.2015.182.185

24. Churnosov MI, Altuchova OB, Demakova NA, et al. Associations of cytokines genetic variants with myomatous knots sizes. Research Journal of 
Pharmaceutical, Biological and Chemical Sciences. 2014;5(6):1344-1347.

25.Reshetnikov EA, Akulova LYu, Dobrodomova IS, et al. [Study of the role of body mass index in the nature of associations of genetic polymorphisms of vasoactive hormones with blood pressure in women at the end of pregnancy]. Nauchnyye vedomosti Belgorodskogo gosudarstvennogo universiteta. Seriya: Meditsina. Farmatsiya. 2011;4(99):153159. Russian.

26. Krivoshei IV, Altuchova OB, Polonikov $\mathrm{AV}$, et al. Bioinformatic analysis of the liability to the hyperplastic processes of the uterus. Research Journal of Pharmaceutical, Biological and Chemical Sciences. 2015;6(5):1563-1566.

27.Ponomarenko IV, Reshetnikov EA, Polonikov $\mathrm{AV}$, et al. [The polymorphic locus rs 314276 of the LIN28B gene is associated with the age of menarche in women of the Central Black Earth Region of Russia]. Akusherstvo i ginekologiya. 2019;2:98-104. Russian. DOI: 10.18565/aig.2019.2.98-104

28. Reshetnikov EA, Akulova LYu, Orlova VS, et al. [Associations of genetic polymorphism of angiotensin-converting enzyme with indicators of blood pressure in pregnant women, depending on body mass index]. Nauchnyye vedomosti Belgorodskogo gosudarstvennogo universiteta. Seriya: Meditsina. Farmatsiya. 2016;19(240):89-95. Russian.

\section{Информация об авторе}

Олег Васильевич Головченко, кандидат медицинских наук, доцент кафедры акушерства и гинекологии, ФГАОУ ВО «Белгородский государственный национальный исследовательский университет», E-mail: gol.doc@ mail.ru.

\section{Information about the author}

Oleg V. Golovchenko, Candidate of Medical Sciences, Associate Professor of the Department of Obstetrics and Gynecology, Belgorod State National Research University, E-mail: gol.doc@mail.ru.

Статья поступила в редакцию 11 июня 2019 г. Receipt date 2019 June 11.

Статья принята к публикации 6 сентября 2019 г. Accepted for publication 2019 September 6. 